\title{
SYNTHESES AND STRUCTURAL STUDIES ON COORDINATION COMPOUNDS OF POLYSTYRENE- ANCHORED SCHIFF BASE WITH SOME METAL IONS
}

\author{
DINESH KUMAR ${ }^{a}$ PRAVEEN KUMAR GUPTA*b AND ARUN SYAMAL
}

\begin{abstract}
${ }^{a}$ Department of Chemistry, National Institute of Technology, Kurukshetra 136119, Haryana, India ${ }^{b}$ Department of Chemistry, Haryana College of Technology \& Management, Kaithal, 136027, Haryana, India, 'School of Coordination Chemistry', D Wing, Ushanagar, Bhandup, Mumbai, 400 078, India
\end{abstract}

(Received: November 22, 2012 - Accepted: December 26, 2013)

\begin{abstract}
Aminomethylated polystyrene $\left(\mathrm{PSCH}_{2}-\mathrm{NH}_{2}\right)$ reacts with 3-ethoxysalicylaldehyde in equimolar amounts to produce monobasic bidentate (ON donor) polystyrene-anchored Schiff base (PS-LH). The latter upon refluxing with metal the ions in 1:2 molar ratios gives polystyrene-anchored coordination compounds of types: $\left[\mathrm{PSCH}_{2}-\mathrm{LM}(\mathrm{OAc})(\mathrm{DMF})\right]$ (where $\left.\mathrm{M}=\mathrm{Cd}, \mathrm{Co}, \mathrm{Cu}, \mathrm{Zn}, \mathrm{UO}_{2}\right),\left[\mathrm{PSCH}_{2}-\mathrm{LNi}(\mathrm{OAc})(\mathrm{DMF})_{3}\right],\left[\mathrm{PSCH}_{2}-\mathrm{LFeCl}_{2}\left(\mathrm{DMF}_{2}\right],\left[\mathrm{PSCH}_{2}-\mathrm{LMCl}\left(\mathrm{CH}_{3} \mathrm{OH}\right)\right](\right.$ where $\mathrm{M}=\mathrm{Cd}, \mathrm{Zn}$ ) and $\left[\mathrm{PSCH}_{2}-\mathrm{LMoO}_{2}(\mathrm{acac})\right]$. The polystyrene-anchored compounds have been characterized on the basis of elemental analyses, spectral (IR, reflectance, ESR) and magnetic susceptibility measurements. The polystyrene-anchored $\mathrm{Co}(\mathrm{II}), \mathrm{Cu}(\mathrm{II}), \mathrm{Ni}(\mathrm{II})$ and $\mathrm{Fe}(\mathrm{III})$ compounds are paramagnetic, while others are diamagnetic. $\mathrm{Co}(\mathrm{II})$ and $\mathrm{Cu}(\mathrm{II})$ compounds are square-planar; $\mathrm{Zn}(\mathrm{II})$ and $\mathrm{Cd}(\mathrm{II})$ compounds are tetrahedral; $\mathrm{Ni}(\mathrm{II}), \mathrm{Fe}(\mathrm{III}), \mathrm{MoO}{ }_{2}(\mathrm{VI})$ and $\mathrm{UO}$ ( $(\mathrm{VI})$ compounds are octahedral.
\end{abstract}

Keywords: polystyrene-anchored, Schiff base, coordination compounds, diamagnetic, magnetically dilute.

\section{INTRODUCTION}

The polymer-anchored coordination compounds have a great interest due to there wide application field. Metal complexes on polymer support have shown various uses in organic synthesis ${ }^{1}$, curing agent for epoxy resin ${ }^{2}$, as catalyst ${ }^{3}$, as ion exchanger ${ }^{4}$ etc. This technique of immobilization on an inert support have drawn much attention due to their easy separation from the reaction mixture leading to operational flexibility, selectivity, efficiency, stability and ease of handling and economy in various industrial processes. Insoluble polymer supports are more frequently used as inert support for immobilizing the transition metal over cross-linked chloromethylated polystyrene ${ }^{5}$, poly(h ydroxylethylmethacrylate), poly(glycidylmethacrylate) ${ }^{6,7}$ and silica ${ }^{8}$. Among organic polymers polystyrene has been extensively used as support with a wide range of functional groups incorporated in it to bind the metal into the polymer. Cross-linked polystyrene with specific properties are widely used as catalyst as they are inert, non-volatile, non-toxic and recyclable. Polymeranchored metal catalysts are known to catalyze various reactions: epoxidation of alkanes, alkenes ${ }^{9,10}$, oxidation of aromatic alcohols ${ }^{11}$, hydrogenation of alkenes $^{12}$, reduction of ketones and nitriles ${ }^{13}$ etc. In the present work, we report the synthesis and characterization of aminomethylated polystyrene-anchored Schiff base (I) and its coordination compounds with $\mathrm{Cd}(\mathrm{II}), \mathrm{Co}(\mathrm{II}), \mathrm{Cu}(\mathrm{II})$, $\mathrm{Ni}(\mathrm{II}), \mathrm{Zn}(\mathrm{II}), \mathrm{Fe}(\mathrm{III}), \mathrm{MoO}_{2}(\mathrm{VI})$ and $\mathrm{UO}_{2}(\mathrm{VI})$.<smiles>C=Cc1ccc(C/N=C/c2cccc(OCC)c2O)cc1</smiles>

$\mathrm{PSCH}_{2}-\mathrm{LH}(\mathrm{I})$, where $-\mathrm{CH}_{2}-1$

\section{EXPERIMENTAL}

\subsection{Materials}

Aminomethylated polystyrene beads $\left(\mathrm{PSCH}_{2}-\mathrm{NH}_{2}\right)$ (containing 1.17 mmol of $\mathrm{NH}_{2}$ per $\mathrm{g}$ of resin and $1 \%$ crosslinked with divinylbenzene) [Sigma Chemical Co.(USA)], 3-ethoxysalicylaldehyde [Aldrich Chemical Co.(USA)] and cadmium chloride hemipentahydrate [SD's Fine Chemicals], iron(III) chloride(anhydrous), cobalt(II) acetate tetrahydrate, cadmium(II) acetate tetrahydrate, dioxouranium(VI) acetate tetrahydrate [BDH]; nickel(II) acetate
tetrahydrate[Fluka AG(Switzerland)]; zinc(II) acetate dihydrate, zinc(II) chloride dihydrate[SD's Fine Chemicals]; copper(II) acetate monohydrate, Dimethylfomamide, methanol, acetone[Ranbaxy Laboratories Ltd.] were used for the synthesis. Bis(acetylacetonato)dioxomolybdenum(VI) was synthesized by following the published procedure ${ }^{14}$. The solvents were dried on molecular sieves prior to use.

\subsection{Analyses and physical measurements}

IR spectra were recorded using $\mathrm{KBr}$ pellets $\left(4000-400 \mathrm{~cm}^{-1}\right)$ on a Nicolet Fourier transform infrared spectrophotometer calibrated with polystyrene. Reflectance spectra were recorded on a Beckmann DU spectrophotometer attached with a reflectance arrangement. Magnetic susceptibility measurements were carried out at room temperature, using double ended one sided sealed Gouy tube and $\mathrm{Hg}\left[\mathrm{Co}(\mathrm{NCS})_{4}\right]$ as the standard ${ }^{21}$. The diamagnetic corrections were computed using the procedure specially developed for the polymer supported coordination compounds. The magnetic susceptibilities for diamagentism of ligand and metal ions were corrected for temperature independent paramagnetism term(TIP). The TIP values were taken as $200 \mathrm{x}$ $10^{-6} \mathrm{cgs}$ units for $\mathrm{Co}(\mathrm{II})$ and $\mathrm{Ni}(\mathrm{II})$ and $60 \times 10^{-6} \mathrm{cgs}$ units for $\mathrm{Cu}(\mathrm{II})$. The TIP value for $\mathrm{Fe}(\mathrm{III})$ was taken as zero as the high spin $\mathrm{d}^{5}$ system has a ${ }^{6} \mathrm{~A}_{1 \mathrm{~g}}$ ground state.

2.3 Synthesis of polystyrene-anchored ligand $\left(\mathrm{PSCH}_{2}-\mathrm{LH}\right)(\mathrm{I})$

$\mathrm{PSCH}_{2}-\mathrm{NH}_{2}(1.0 \mathrm{~g})$ was suspended in DMF $(20 \mathrm{~mL})$ for $45 \mathrm{~min}$. To this suspension, a DMF solution $(60 \mathrm{~mL})$ of 3-ethoxysalicylaldehyde (LH) $(0.58 \mathrm{~g}$, $3.51 \mathrm{mmol}$ ) was added. The mixture was refluxed for $8 h$ and then cooled to room temperature. The cream coloured product obtained was suction filtered, washed several times with $\mathrm{DMF}, \mathrm{MeOH}, \mathrm{EtOH}$ and petroleum ether and dried in vacuo.

2.4. Syntheses of polystyrene-anchored coordination compounds, $\left[\mathrm{PSCH}_{2}-\mathrm{LM}(\mathrm{OAc})(\mathrm{DMF})\right]\left(\right.$ where $\left.\mathrm{M}=\mathrm{Co} \mathrm{Cd}, \mathrm{Cu}, \mathrm{Zn}, \mathrm{UO}_{2}\right)$ and $\left[\mathrm{PSCH}_{2}-\right.$ $\left.\mathrm{LNi}(\mathrm{OAAc})(\mathrm{DMF})_{3}\right]$

$\mathrm{PSCH}_{2}-\mathrm{LH}(\mathbf{I})(0.5 \mathrm{~g}, 0.58 \mathrm{mmol})$ was suspended in DMF $(15 \mathrm{~mL})$ for 1 $h$. To this suspension, a DMF solution (30-60 mL) of appropriate metal acetate $(1.17 \mathrm{mmol})$ was added. The mixture was heated under reflux, while stirring for 5-7 $h$. The products obtained were cooled to room temperature and then suction filtered, washed several times with DMF, $\mathrm{MeOH}, \mathrm{EtOH}$ and $\mathrm{Me}_{2} \mathrm{CO}$. The compounds were dried as mentioned above.

2.5. Synthesis of $\left[\mathrm{PSCH}_{2}-\mathrm{LFeCl}_{2}(\mathrm{DMF})_{2}\right]$

$\mathrm{PSCH}_{2}-\mathrm{LH}(\mathbf{I})(0.5 \mathrm{~g}, 0.58 \mathrm{mmol})$ was suspended in DMF $(15 \mathrm{~mL})$ for 1 $h$. To this suspension, a DMF solution $(30 \mathrm{~mL})$ of anhydrous iron(III) chloride $(0.20 \mathrm{~g}, 1.17 \mathrm{mmol})$ was added. The mixture was refluxed under anhydrous conditions, while stirring magnetically for $8 h$. The reddish brown product obtained was cooled to room temperature and suction filtered, washed several times with $\mathrm{DMF}, \mathrm{MeOH}, \mathrm{EtOH}$ and $\mathrm{Me}_{2} \mathrm{CO}$. The compound was dried as mentioned above.

2.6. Syntheses of $\left[\mathrm{PSCH}_{2}-\mathrm{LMCl}(\mathrm{MeOH})\right]$ (where $\mathrm{M}=\mathrm{Zn}$ and $\left.\mathrm{Cd}\right)$

$\mathrm{PSCH}_{2}-\mathrm{LH}$ (I) $(0.5 \mathrm{~g}, 0.58 \mathrm{mmol})$ was suspended in $\mathrm{MeOH}(15 \mathrm{~mL})$ for $1 \mathrm{~h}$. To this suspension, a $\mathrm{MeOH}$ solution $(30 \mathrm{~mL})$ of appropriate metal(II) 
chloride $(1.17 \mathrm{mmol})$ was added. The mixture was heated under reflux, while stirring magnetically for $5 h$. The products obtained were cooled to room temperature and then suction filtered, washed several times with $\mathrm{DMF}, \mathrm{MeOH}$, $\mathrm{EtOH}$ and $\mathrm{Me}_{2} \mathrm{CO}$. The compounds were dried as mentioned above.

2.7. Synthesis of $\left[\mathrm{PSCH}_{2}-\mathrm{LMoO}_{2}\right.$ (acac)]

$\mathrm{PSCH}_{2}-\mathrm{LH}(\mathbf{I})(0.5 \mathrm{~g}, 0.58 \mathrm{mmol})$ was suspended in DMF $(15 \mathrm{~mL})$ for $1 \mathrm{~h}$. To this suspension, a DMF solution $(30 \mathrm{~mL})$ of bis(acetylacetonato) dioxomolybdenum(VI) $(0.38 \mathrm{~g}, 1.17 \mathrm{mmol})$ was added. The mixture was heated under reflux, while stirring magnetically for $7 h$. The yellow coloured product obtained was cooled to room temperature and then suction filtered, washed several times with $\mathrm{DMF}, \mathrm{MeOH}, \mathrm{EtOH}$ and $\mathrm{Me}_{2} \mathrm{CO}$. The compound was dried as mentioned above.

\section{RESULTS AND DISCUSSION.}

The nucleophilic addition reaction followed by the elimination of one $\mathrm{H}_{2} \mathrm{O}$ molecule between $\mathrm{PSCH}_{2}-\mathrm{NH}_{2}$ and $\mathrm{LH}$ in DMF results in the formation of $\mathrm{PSCH}_{2}-\mathrm{LH}(\mathbf{I})$

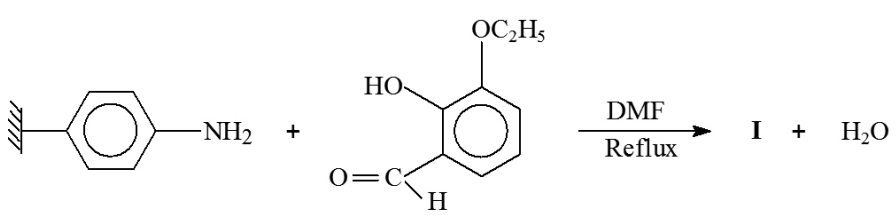

$\mathrm{PSCH}_{2}-\mathrm{LH}$ reacts with metal complex/metal salts in 1:2 ratio for $5-8 h$ in DMF and forms polystyrene-anchored coordination complexes as shown below:

$$
\begin{aligned}
& \underset{\mathrm{PSCH}}{\mathrm{P}-\mathrm{LH}}+\mathrm{M}(\mathrm{OAc})_{2} \cdot \mathrm{xH}_{2} \mathrm{O} \underset{\text { reflux }}{\stackrel{\mathrm{DMF}}{\longrightarrow}}\left[\mathrm{PSCH}_{2}-\mathrm{LM}(\mathrm{OAc})(\mathrm{DMF})\right]+ \\
& \mathrm{HOAc}+\mathrm{xH}_{2} \mathrm{O} \text { reflux }\left[\mathrm{M}=\mathrm{Co}, \mathrm{Cu}, \mathrm{Zn}, \mathrm{Cd} \text { and } \mathrm{UO}_{2}\right]
\end{aligned}
$$

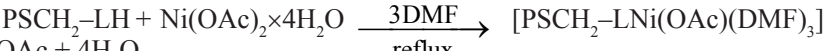

$$
\begin{aligned}
& +\mathrm{HOAc}+4 \mathrm{H}_{2} \mathrm{O} \\
& \text { reflux } \\
& \mathrm{PSCH}_{2}-\mathrm{LH}+\mathrm{FeCl}_{3} \underset{\text { reflux }}{\stackrel{2 \mathrm{DMF}}{\longrightarrow}}\left[\mathrm{PSCH}_{2}-\mathrm{LFeCl}_{2}(\mathrm{DMF})_{2}\right]+\mathrm{HCl} \\
& \mathrm{PSCH}_{2}-\mathrm{LH}+\mathrm{MCl}_{2} \underset{\text { reflux }}{\stackrel{\mathrm{Me} \mathrm{OH}}{\longrightarrow}} \underset{\left[\mathrm{M}=\mathrm{Zn}_{2} \text { and } \mathrm{Cd}\right]}{\left[\mathrm{PSCH}_{3}-\mathrm{LMCl}(\mathrm{MeOH})\right]+\mathrm{HCl}}
\end{aligned}
$$$$
\mathrm{PSCH}_{2}-\mathrm{LH}+\mathrm{MoO}_{2}(\mathrm{acac})_{2} \underset{\text { reflux }}{\stackrel{\mathrm{DMF}}{\longrightarrow}}\left[\mathrm{PSCH}_{2}-\mathrm{LMoO}_{2}(\mathrm{acac})\right]+\mathrm{acacH}
$$

The compounds are insoluble in water as well as other organic solvents. The percent reaction conversion (PRC) of the polystyrene-anchored coordination compounds varies from 33.0 to 98.0 and the metal binding capacity ${ }^{17}$ (MBC) $\{\mathrm{MBC}=[\mathrm{M} \%$ (observed) $\times 10] /($ atomic weight of metal $)\}$ of $\mathrm{PSCH}_{2}-\mathrm{LH}(\mathbf{I})$ in the range $0.28-0.75 \mathrm{mmol} / \mathrm{g}$ of resin (Table 1 ). The metal ions in polystyreneanchored coordination compounds are leached with hot diluted $\mathrm{OAc} / \mathrm{HCl}$ at $\mathrm{pH}$ $4-5.5$ and the leached resin can be used for the formation of other coordination compounds.

Table 1. Colour and Analytical Data of Polystyrene-Anchored Coordination Compounds.

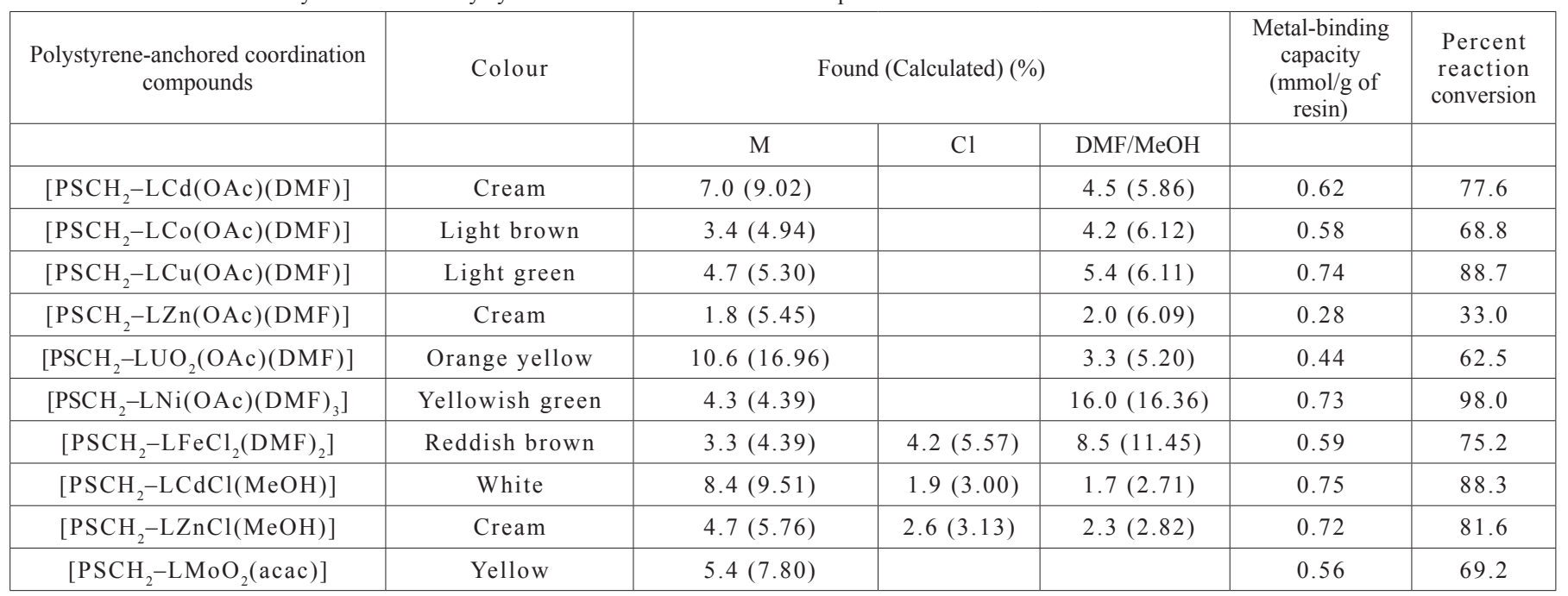

The prominent IR bands of polystyrene-anchored coordination compounds are shown in Table 2. The $v(\mathrm{C}=\mathrm{N})$ (azomethine) stretch of $\mathrm{PSCH}_{2}-\mathrm{LH}(\mathrm{I})$ occurs at $1630 \mathrm{~cm}^{-1}$ and this band shifts to lower energy by $5-20 \mathrm{~cm}^{-1}$ in polystyrene-anchored coordination compounds. The positive shift of $v(\mathrm{C}-\mathrm{O})$ (phenolic) stretch of I from $1510 \mathrm{~cm}^{-1}$ to higher energy by $\leq 10 \mathrm{~cm}^{-1}$ in the coordination compounds indicates the involvement of phenolic $\mathrm{O}$ atom towards coordination ${ }^{15}$. The data preclude the presence of dimetallic structure, as in such a case $v(\mathrm{C}-\mathrm{O})$ (phenolic) stretch usually shifts to higher energy by $>10 \mathrm{~cm}^{-1}$. Thus, $\mathrm{PSCH}_{2}-\mathrm{LH}$ acts as a bidentate ligand coordinating through the phenolic $\mathrm{O}$ and azomethine $\mathrm{N}$ atoms. The $v_{\mathrm{sy}}(\mathrm{OAc})$ and $v_{\text {asy }}(\mathrm{OAc})$ stretches of the noncoordinated acetate ion occurs at 1416 and $1560 \mathrm{~cm}^{-1}$ respectively ${ }^{16}$. The present coordination compounds containing coordinated acetato group show these bands in the regions: $1370-1395 \mathrm{~cm}^{-1}$ and $1575-1595 \mathrm{~cm}^{-1}$ respectively. The energy difference (205-215 $\left.\mathrm{cm}^{-1}\right)$ between $v_{\mathrm{sy}}(\mathrm{OAc})$ and $v_{\text {asy }}(\mathrm{OAc})$ is an indicative of monodentate nature of coordinated acetato group, since in case of bidentate coordination ${ }^{16}$, the energy difference is $<144 \mathrm{~cm}^{-1}$. MeOH exhibits a band at $1034 \mathrm{~cm}^{-1}$ due to the $v(\mathrm{C}-\mathrm{O})$ stretch and this band shifts to lower energy by $65 \mathrm{~cm}^{-1}$ in $\left[\mathrm{PSCH}_{2}-\mathrm{LMCl}(\mathrm{MeOH})\right]$ (where $\mathrm{M}=\mathrm{Zn}$ and $\mathrm{Cd}$ ) indicating $\mathrm{MeOH}$ coordination ${ }^{15}$. DMF shows a band at $1680 \mathrm{~cm}^{-1}$ assigned to the $v(\mathrm{C}=\mathrm{O})$ stretch and this band shifts to lower energy by $20-50 \mathrm{~cm}^{-1}$ in the coordination compounds indicating the $\mathrm{O}$ coordination of $\mathrm{DMF}^{17}$. $\left[\mathrm{PSCH}_{2}-\mathrm{LMoO}_{2}(\mathrm{acac})\right]$ exhibits two bands, due to $v_{\text {acy }}(\mathrm{O}=\mathrm{Mo}=\mathrm{O})$ and $v_{\mathrm{sy}}(\mathrm{O}=\mathrm{Mo}=\mathrm{O})$ stretches occurring at 910 and $940 \mathrm{~cm}^{-1}$ respectively characteristics of a cis- $\mathrm{MoO}_{2}$ moiety. These bands lie in the usual ranges $\left[840-925 \mathrm{~cm}^{-1}, v_{\text {bry }}(\mathrm{O}=\mathrm{Mo}=\mathrm{O})\right.$ and $892-964 \mathrm{~cm}^{-1}$, $v(\mathrm{O}=\mathrm{Mo}=\mathrm{O})$ stretches] respectively, reported for the majority of $\mathrm{MoO}_{2}(\mathrm{VI})$ compounds ${ }^{18}$. $\left[\mathrm{PSCH}_{2}-\mathrm{LUO}_{2}(\mathrm{OAc})(\mathrm{DMF})\right]$ shows a band at $900 \mathrm{~cm}^{-1}$ assigned to $v(\mathrm{O}=\mathrm{U}=\mathrm{O})$ stretch and this band lies within the usual range $(870-950 \mathrm{~cm}$ $\left.{ }^{1}\right)$ reported for the majority of $\mathrm{UO}_{2}(\mathrm{VI})$ compounds ${ }^{17}$. The observation of only the $v_{\text {avy }}(\mathrm{O}=\mathrm{U}=\mathrm{O})$ band suggests the trans $-\mathrm{UO}_{2}$ structure. The force constant $\left(\mathrm{f}_{\mathrm{U}-\mathrm{O}}\right)^{17 \mathrm{1y}}$ is $6.73 \mathrm{mdyn} / \AA$. The U-O bond distance is $1.74 \AA$ and lies in the usual range $(1.60-1.92 \AA)$ reported for the majority of the $\mathrm{UO}_{2}(\mathrm{VI})$ compounds.

The magnetic susceptibility measurements at room temperature for polystyrene-anchored compounds are presented in Table 3. The magnetic moment $(2.53$ B.M.) of $\mathrm{Co}(\mathrm{II})$ compound suggests its square planargeometry ${ }^{19}$. The magnetic moment (1.92 B.M.) of $\mathrm{Cu}(\mathrm{II})$ compound indicates its magnetically dilute nature ${ }^{19}$. The magnetic moments of $\mathrm{Ni}$ (II) and $\mathrm{Fe}$ (III) compounds are 3.20 and 5.94 B.M. respectively suggesting their octahedral geometries ${ }^{19}$. The $\mathrm{Cd}(\mathrm{II}), \mathrm{Zn}(\mathrm{II}), \mathrm{MoO}_{2}(\mathrm{VI})$ and $\mathrm{UO}_{2}(\mathrm{VI})$ coordination compounds are diamagnetic. The data suggest an octahedral structure for $\mathrm{MoO}_{2}(\mathrm{VI})$ and $\mathrm{UO}_{2}(\mathrm{VI})$ compounds and tetrahedral structure for $\mathrm{Zn}(\mathrm{II})$ and $\mathrm{Cd}(\mathrm{II})$ coordination compounds. 
Table 2. IR Spectral Data $\left(\mathrm{cm}^{-1}\right)$ of Polystyrene-Anchored Ligand and its Coordination Compounds.

\begin{tabular}{|c|c|c|c|c|c|}
\hline $\begin{array}{c}\text { Polystyrene-anchored ligand/ } \\
\text { coordination compounds }\end{array}$ & $\begin{array}{c}v(\mathrm{C}=\mathrm{N}) \\
(\text { azomethine })\end{array}$ & $v(\mathrm{C}-\mathrm{O})($ phenolic $)$ & $v(\mathrm{C}=\mathrm{O})(\mathrm{DMF})$ & $v_{\text {sy }}(\mathrm{OAc})$ & $v_{\text {asy }}(\mathrm{OAc})$ \\
\hline $\mathrm{PSCH}_{2}-\mathrm{LH}$ & 1630 & 1510 & - & - \\
\hline$\left[\mathrm{PSCH}_{2}-\mathrm{LCd}(\mathrm{OAc})(\mathrm{DMF})\right]$ & 1610 & 1515 & 1660 & 1380 & 1595 \\
\hline$\left[\mathrm{PSCH}_{2}-\mathrm{LCo}(\mathrm{OAc})(\mathrm{DMF})\right]$ & 1610 & 1515 & 1645 & 1370 & 1575 \\
\hline$\left[\mathrm{PSCH}_{2}-\mathrm{LCu}(\mathrm{OAc})(\mathrm{DMF})\right]$ & 1610 & 1520 & 1650 & 1380 & 1580 \\
\hline$\left[\mathrm{PSCH}_{2}-\mathrm{LZn}_{(\mathrm{OAc})(\mathrm{DMF})]}\right.$ & 1620 & 1515 & 1635 & 1385 & 1595 \\
\hline$\left[\mathrm{PSCH}_{2}-\mathrm{LUO}_{2}(\mathrm{OAc})(\mathrm{DMF})\right]$ & 1610 & 1520 & 1650 & 1370 & 1585 \\
\hline$\left[\mathrm{PSCH}_{2}-\mathrm{LNi}_{(\mathrm{OAc})(\mathrm{DMF})}\right]$ & 1625 & 1520 & 1630 & 1395 & 1595 \\
\hline$\left[\mathrm{PSCH}_{2}-\mathrm{LFeCl}_{2}(\mathrm{DMF})_{2}\right]$ & 1625 & 1520 & 1645 & - & - \\
\hline$\left[\mathrm{PSCH}_{2}-\mathrm{LCdCl}_{(\mathrm{MeOH})}\right]$ & 1615 & 1515 & - & - & - \\
\hline$\left.\left[\mathrm{PSCH}_{2}-\mathrm{LZnCl}_{2} \mathrm{MeOH}\right)\right]$ & 1620 & 1515 & - & - & - \\
\hline$\left[\mathrm{PSCH}_{2}-\mathrm{LMoO}_{2}(\mathrm{acac})\right]$ & 1615 & 1515 & - & - & - \\
\hline
\end{tabular}

The solid state reflectance spectral data of the polystyrene-anchored compounds are presented in Table 3. $\left[\mathrm{PSCH}_{2}-\mathrm{LCo}(\mathrm{OAc})(\mathrm{DMF})\right]$ exhibits two bands at 8800 and $25000 \mathrm{~cm}^{-1}$ assigned to ${ }^{1} A_{\mathrm{g}} \rightarrow{ }^{1} B_{2 \mathrm{~g}}$ and ${ }^{1} A_{\mathrm{g}} \rightarrow{ }^{1} B_{1 \mathrm{~g}}$ transitions respectively suggesting square planar symmetry ${ }^{20}$. [PSCH $\left.-\mathrm{LCu}(\mathrm{OAc})(\mathrm{DMF})\right]$ displays an asymmetric band at $17900 \mathrm{~cm}^{-1}$ due to ${ }^{2} B_{\mathrm{g}} \rightarrow{ }^{2} A_{1 \mathrm{~g}},{ }^{2} B_{2 \mathrm{~g}}$ and ${ }^{2} E_{\mathrm{g}}$ transitions, characteristic of square- planar symmetry ${ }^{20}$. [PSCH ${ }_{2}^{2}-\mathrm{LNi}(\mathrm{OAc})(\mathrm{DMF})_{3}$ ] displays two bands at 9250 and $16200 \mathrm{~cm}^{-1}$ due to ${ }^{3} A_{2 g} \rightarrow{ }^{3} T_{2 g}\left(v_{1}\right)$ and ${ }^{3} A_{2 g} \rightarrow{ }^{3} T_{1 g}(F)\left(v_{2}\right)$ transitions respectively, suggesting an octahedral structure ${ }^{20}$. The $v_{2}: v_{1}$ value of the compound is 1.75 which agrees well with the reported range (1.60-1.82) observed for the majority of the $\mathrm{Ni}$ (II) octahedral compounds ${ }^{20}$. Another band due ${ }^{3} A_{2 \mathrm{~g}} \rightarrow$ ${ }^{3} T_{1 \mathrm{~g}}(P)\left(v_{3}\right)$ transition could not be located since it is probably merged with the strong charge transfer band. $\left[\mathrm{PSCH}_{2}-\mathrm{LFeCl}_{2}(\mathrm{DMF})_{2}\right]$ (II) shows three spectral bands at 13000,15800 and $20000 \mathrm{~cm}^{-1}$ due to ${ }^{6} A_{1 \mathrm{~g}} \rightarrow{ }^{4} T_{1 \mathrm{~g}}(G),{ }^{6} A_{1 \mathrm{~g}} \rightarrow{ }^{4} T_{2 \mathrm{~g}}(G)$ and ${ }^{6} A_{1 \mathrm{~g}} \rightarrow{ }^{4} A_{1 \mathrm{~g}}(G)$ transitions respectively, suggesting an octahedral structure ${ }^{20}$.

Table 3. Magnetic Susceptibility Measurements and Reflectance Spectral Data of Polystyrene-Anchored Coordination Compounds.

\begin{tabular}{|c|c|c|c|c|}
\hline $\begin{array}{c}\text { Polystyrene-anchored coordination } \\
\text { compounds }\end{array}$ & $\begin{array}{c}\text { Diamagnetic } \\
\text { correction } \\
\chi_{\text {dia }}\left(10^{-6} \text { cgs units }\right)\end{array}$ & $\begin{array}{c}\chi_{\mathrm{M}}^{\text {corr }} \\
\left(10^{-6} \text { cgs units }\right)\end{array}$ & $\begin{array}{c}\text { Magnetic moment } \\
\text { (B.M. })(\text { Temp. K })\end{array}$ & $\begin{array}{c}v_{\text {max }} \\
\left(\mathrm{cm}^{-1}\right)\end{array}$ \\
\hline$\left[\mathrm{PSCH}_{2}-\mathrm{LCo}(\mathrm{OAc})(\mathrm{DMF})\right]$ & -813 & 2746 & $2.53(291)$ & 8800 \\
\hline$\left[\mathrm{PSCH}_{2}-\mathrm{LCu}(\mathrm{OAc})(\mathrm{DMF})\right]$ & -649 & 1587 & $1.92(289)$ & 17900 \\
\hline$\left[\mathrm{PSCH}_{2}-\mathrm{LNi}(\mathrm{OAc})(\mathrm{DMF})_{3}\right]$ & -511 & 4394 & $3.20(291)$ & 16250 \\
\hline$\left[\mathrm{PSCH}_{2}-\mathrm{LFeCl}_{2}(\mathrm{DMF})_{2}\right]$ & -806 & 15036 & $5.94(293)$ & 13000 \\
\hline
\end{tabular}

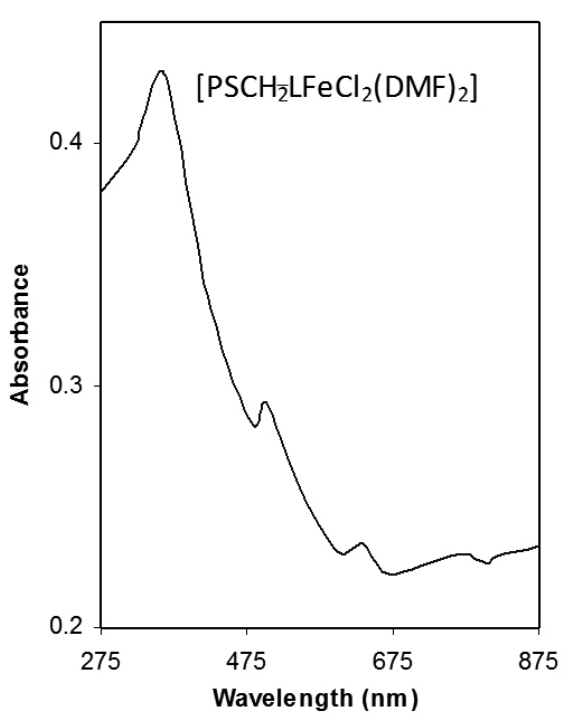

II
ESR spectrum of $\left[\mathrm{PSCH}_{2}-\mathrm{LCu}(\mathrm{OAc})(\mathrm{DMF})\right]$ was recorded at liquid nitrogen temperature in polycrystalline solids using DPPH as a field marker. Hyperfine coupling due to copper is resolved in both the parallel and perpendicular regions. The spectrum shows well resolved four hyperfine lines with no super-hyperfine lines. However, the half field signal $\left(\Delta M_{\mathrm{s}}=\right.$ $\pm 2, \sim 1600$ gauss) corresponding to the $\mathrm{Cu}-\mathrm{Cu}$ interaction was not observed and conclusively proves the absence of the magnetic exchange interaction in $\left[\mathrm{PSCH}_{2}-\mathrm{LCu}(\mathrm{OAc})(\mathrm{DMF})\right]$. The spin-Hamiltonian parameters are: $g_{\|}=2.25$, $g_{\perp}=2.11, A_{\|}=1.68 \times 10^{-2} \mathrm{~cm}^{-1}, A=3.9 \times 10^{-3} \mathrm{~cm}^{-1}, G=2.3, \alpha^{2}=0.80$, $\left(\alpha^{\prime}\right)^{2}=0.27, \kappa=0.54$ and $P_{d}=1.66 \times 10^{-2} \mathrm{~cm}^{-1}$. The $\mathrm{g}$ tensor values of $\mathrm{Cu}(\mathrm{II})$ complex can be used to derive the ground state. In square planar complexes, the unpaired electron lies in the $d_{x^{2}-y^{2}}$ orbital giving ${ }^{2} B_{1 \mathrm{~g}}$ as the ground state with $\mathrm{g}_{\|}>\mathrm{g}_{\perp}$. From the observed values, it is clear that $\mathrm{g}_{\|}>\mathrm{g}_{\perp}$, which suggests that the complex is square planar. Also it is supported by the fact that the unpaired electron lies predominantly in the $d_{x^{2}-y^{2}}$ orbital ${ }^{21}$. The geometric parameter $(G)$, a measure of the exchange interaction ${ }^{22}$, was found to be 2.3 and this value lies within the range 2.1-3.8, consistent with the ground state $d_{x^{2}-y^{2}}$. The molecular orbital coefficient, i.e. covalency parameter $\alpha_{\text {c }}^{2}$ (a measure of covalency of the in-plane $\sigma$-bonding) has been calculated using the equation ${ }^{21}$ : $\alpha_{\mathrm{Cu}}^{2}=-\left(A_{\|} / 0.036\right)+\left(\mathrm{g}_{\|}-2.0023\right)+3 / 7\left(\mathrm{~g}_{\perp}-2.0023\right)+0.04$, where $\alpha$ is related to the overlap integral $(S)$ between the metal $d_{x^{2}-y^{2}}$ and ligand orbitals according to the relation: $\alpha^{2}-2 \alpha \alpha^{\prime} S+\left(\alpha^{\prime}\right)^{2}=1$. A value of $\alpha_{\mathrm{Cu}}^{2}=0.5$ indicates the complete covalent bonding, while the value of $\alpha_{\mathrm{Cu}}^{2}=1.0$ suggests complete ionic bonding. The observed value $\left(\alpha_{\mathrm{Cu}}^{2}=0.80\right)$ of the $\mathrm{Cu}(\mathrm{II})$ compound is less 
than unity and this indicates that this compound possesses significant covalent character in the M-L bonding ${ }^{21}$. The larger the value of $\left(\alpha^{\prime}\right)^{2}$, the more covalent is the bonding and a value of $\left(\alpha^{\prime}\right)^{2}=0$ indicates a complete ionic bonding. The $\left(\alpha^{\prime}\right)^{2}$ values of 0.52 for the $\mathrm{Cu}(\mathrm{II})$ compound indicates the covalent nature of the compound. The symbol $\kappa P_{\mathrm{d}}$ represents the Fermi contact contribution $(A)$ to the coupling, where $P$ is the dipolar contribution. The value of $P$ and $\kappa$ were calculated using the relation ${ }^{23}: P_{\mathrm{d}}=-\left(A_{\|}-A_{\mathrm{J}}\right) / 0.78$ and $\mathrm{\kappa}=-0.48-\left(A_{\|} / P_{\mathrm{d}}\right)$. The lower value of $P$ in comparison to that of the free ion value $\left(3.5 \times 10^{-2}\right.$ $\mathrm{cm}^{-1}$ ) indicates the covalent interaction in the metal ligand system. A positive value of $\kappa$ predicts that $A_{\|}$should be greater than $A_{\perp}$ and this too has been observed by us.

\section{CONCLUSION}

The Schiff base has been successfully anchored to aminomethylated polystyrene leading to the formation of polymer-anchored ligand. The percent reaction conversion of the polystyrene-anchored coordination compounds varies from 33.0 to 98.0 and the metal binding capacity of $\mathrm{PSCH}_{2}-\mathrm{LH}$ is in the range $0.28-0.75 \mathrm{mmol} / \mathrm{g}$ of resin. The data suggest a square-planar structure (III) for $\left[\mathrm{PSCH}_{2}-\mathrm{LM}(\mathrm{OAc})(\mathrm{DMF})\right](\mathrm{M}=\mathrm{Co}, \mathrm{Cu})$; tetrahedral structures (IV and $\mathbf{V}$ ) for $\left[\mathrm{PSCH}_{2}-\mathrm{LM}(\mathrm{OAc})(\mathrm{DMF})\right]$ and $\left[\mathrm{PSCH}_{2}-\mathrm{LMCl}(\mathrm{MeOH})\right](\mathrm{M}=\mathrm{Zn}$, $\mathrm{Cd})$; octahedral structures (VI, VII, VIII and IX) for $\left[\mathrm{PSCH}_{2}-\mathrm{LNi}(\mathrm{OAc})\right.$ $\left.(\mathrm{DMF})_{3}\right], \quad\left[\mathrm{PSCH}_{2}-\mathrm{LFeCl}_{2}(\mathrm{DMF})_{2}\right], \quad\left[\mathrm{PSCH}_{2}-\mathrm{LMoO}_{2}(\mathrm{acac})\right]$ and $\left[\mathrm{PSCH}_{2}-\right.$ $\left.\mathrm{LUO}_{2}(\mathrm{OAc})(\mathrm{DMF})\right]$ respectively. The polystyrene-anchored $\mathrm{Co}(\mathrm{II}), \mathrm{Cu}(\mathrm{II})$, $\mathrm{Ni}(\mathrm{II})$ and $\mathrm{Fe}(\mathrm{III})$ compounds are paramagnetic, while others are diamagnetic. All coordination compounds are magnetically dilute in nature which is supported by the fact that the reactive functional groups in $\mathrm{PSCH}_{2}-\mathrm{LH}(\mathbf{I})$, are situated every four to five styrene units apart which restricts the two ligands attached to the polymer chain coordinating to the same metal ions.

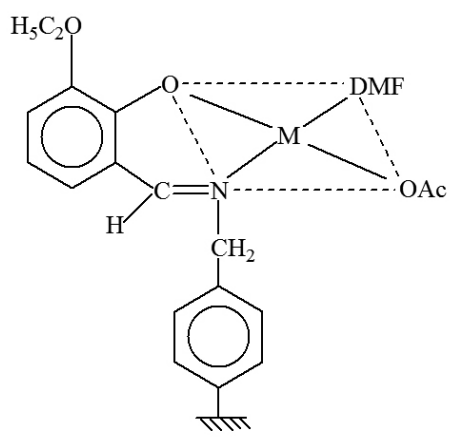

III $(\mathrm{M}=\mathrm{Co}, \mathrm{Cu})$<smiles>COc1cccc(C[PH](=NCc2ccc(C(C)(F)F)cc2)Oc2c(C)cccc2OC)c1</smiles>

IV $(\mathrm{M}=\mathrm{Zn}, \mathrm{Cd})$<smiles>COc1cccc(C)c1OP(=O)(Cc1ccc(C)cc1)N(CO)Cc1ccc(C)cc1</smiles>

$\mathbf{V}(\mathrm{M}=\mathrm{Zn}, \mathrm{Cd})$

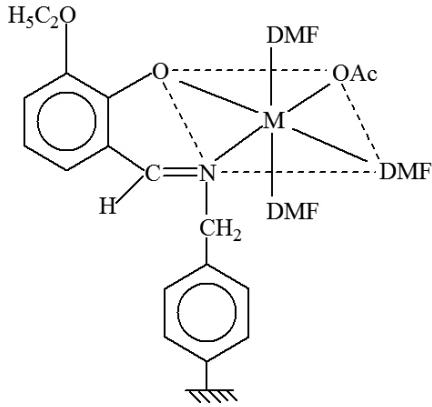

VI

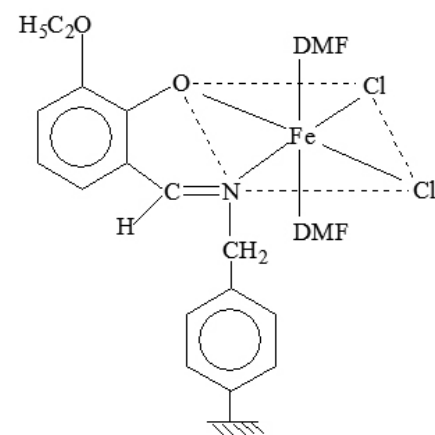

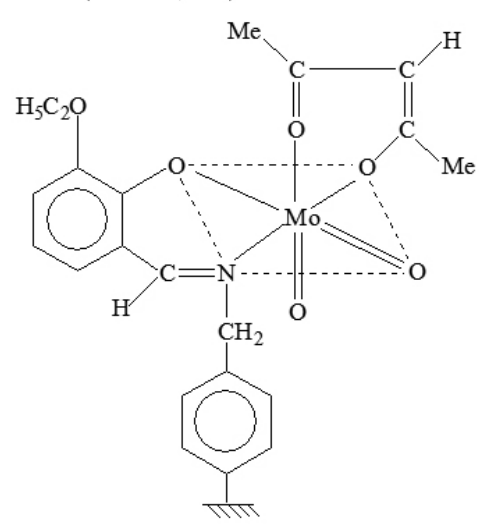

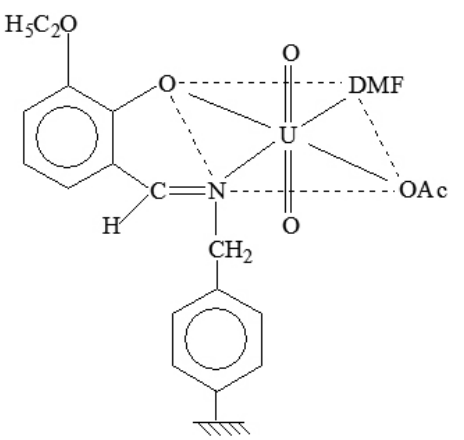




\section{ACKNOWLEDGEMENTS}

One of the author (P.K. Gupta) is grateful to Director of his Institute for his encouragement.

\section{REFERENCES}

1. (a) V.N.R. Pillai, V.K. Haridasan, A. Ajayghosh, J. Org. Chem. 52, 2662 (1987); (b) M. Roice, K.S. Kumar, V.N.R. Pillai, Tetrahedron. 56, 3725 (2000); (c) S. Ficht, M.M. Mulbaier, A. Giannis, Tetrahedron. 57, 4863 (2001).

2. J.O.E. Otaigbe, British Polym. Journal, 20, 53 (1988).

3. M.R. Maurya, M. Kumar, A. Kumar, J. C. Pessoa, Dalton Trans. 4220, (2008).

4. (a) R.G. Phillips, J.S. Fritz, Anal. Chim. Acta. 139, 237 (1982); (b) M. Swapan, C. Ray, J. Das, Indian J. Chem. 27A, 137 (1988).

5. R.B. Merrifield, J. Am. Chem. Soc. 85, 2149 (1963).

6. T. Sa Sak, F. Matsunaga, Bull. Chem. Soc. Jpn. 41, 2440 (1968)

7. A.T. Kapanchan, V.S. Pshezhetskii, V.A. Kabanov, Vysokomal Soed A. 11, 5 (1969).

8. C. Liu, T. Tang, B. Huang, J. Polym. Sci. Part A: Polym. Chem. 39, 2085 (2001).

9. S.A. Patel, S. Sinha, A.N. Mishra, B.V. Kamath, R.N. Ram, J. Mol. Cat. A: Chem. 192, 53 (2003).
10. R. Antony, G.L. Tembe, M. Ravindranathan, R.N. Ram, Eur. Polym. J. 36, 1579 (2000).

11. V.B. Valodkar, G.L. Tembe, M. Ravindranathan, R.N. Ram, H.S. Rama, J. Mol. Cat. A: Chem. 208, 21 (2004).

12. M. Takahashi, A. Tsuji, M. Chiba, S. Itsuno, React. \& Funct. Polym. 65, 1 (2005).

13. V.B. Valodkar, G.L. Tembe, M. Ravindranathan, R.N. Ram, H.S. Rama, J. Mol. Cat. A: Chem. 202, 47 (2003).

14. G. J. Chen, J. W. McDonald, W. E. Newton, Inorg. Chem. 15, 2612 (1976).

15. A. Syamal, D. Kumar, Indian J. Chem. 24A, 62 (1985).

16. K. Nakamoto, Infrared and Raman Spectra of Inorganic and Coordination Compounds, $3^{\text {rd }}$ Edn., Wiley Interscience, New York, 1987, p. 232, 249.

17. D. Kumar, A. Syamal, L.K. Sharma, J. Coord. Chem. 61, 1788 (2008)

18. A. Syamal, M.R. Maurya, Coord. Chem. Rev. 95, 183 (1989).

19. F.A. Cotton, G. Wilkinson, C.A. Murillo, M. Bochmann, Advanced Inorganic Chemistry, $6^{\text {th }}$ Edn. John Wiley New York, 1999.

20. (a) A.B.P. Lever, Inorganic Electronic Spectroscopy, Elsevier, Amsterdam, 2nd Edn, 1984.; (b) C.J. Ballhausen, H.B. Gray, Molecular Orbital Theory, New York (1965) p. 118,

21. R. L. Dutta, A. Syamal, Elements of magnetochemistry, $2^{\text {nd }}$ Edn., Affiliated East West Press Pvt. Ltd., New Delhi, 1993, p.7, 227.

22. U.L. Kala, S. Suma, M.R.P. Kurup, S. Krishnan, R.P. John, Polyhedron. 26, 1427 (2007).

23. U. Sakaguchi, A.W. Addison, J. Chem. Soc. Dalton Trans. 600 (1979). 